\title{
Histone deacetylase inhibitors control the transcription and alternative splicing of prohibitin in thyroid tumor cells
}

\author{
CINZIA PUPPIN $^{1}$, NADIA PASSON ${ }^{1}$, ALESSANDRA FRANZONI ${ }^{1-3}$, \\ DIEGO RUSSO $^{2}$ and GIUSEPPE DAMANTE ${ }^{1-3}$
}

\author{
${ }^{1}$ Dipartimento di Scienze e Tecnologie Biomediche, Università di Udine, Udine; \\ ${ }^{2}$ Dipartimento di Scienze Farmacobiologiche, Università di Catanzaro, Catanzaro; \\ ${ }^{3}$ Azienda Ospedaliero-Universitaria 'S. Maria della Misericordia', Udine, Italy
}

Received July 29, 2010; Accepted September 23, 2010

DOI: $10.3892 /$ or.2010.1075

\begin{abstract}
Prohibitin (PHB) is a ubiquitous protein with a number of different molecular functions. PHB is involved in tumorigenesis by exerting either a permissive or blocking action on tumor growth, depending on the cell context. In the present study, we investigated the effects of the histone deacetylase inhibitors (HDACis), trichostatin A (TSA) and sodium butyrate $(\mathrm{NaB})$, on PHB expression in the thyroid tumor cell lines, TPC-1 and FRO. Both TSA and $\mathrm{NaB}$ increased PHB mRNA levels. Transfection experiments showed that the overexpression of HDAC 1 or 2 , but not 3 , inhibited PHB promoter activity. The effects of TSA and $\mathrm{NaB}$ on the two major PHB mRNA splicing isoforms, were also investigated. Both TSA and $\mathrm{NaB}$ decreased the mRNA levels of the shorter isoform, but increased those of the longer isoform. Only the latter isoform contains a 3'UTR, which has been reported to exert a growth suppressive action. Thus, our data demonstrate that HDACis control both PHB transcription and alternative splicing. The effect of HDACis on PHB alternative splicing was not due to the modification of the expression of the ASF/SF2 splicing factor.
\end{abstract}

\section{Introduction}

Prohibitin (PHB) is a ubitiquitously-expressed multifunctional protein with a molecular weight of $\sim 32 \mathrm{kDa}$ (1). It is localized in various intracellular locations including the mitochondria, nuclei, lipid rafts and the cytosol (2-5). In the mitochondria PHB inhibits pyruvate carboxylase (6), an enzyme involved in the tricarboxylic acid cycle (7). Moreover, PHB exerts a chaperone function, protecting newly imported proteins from degradation (8). The knockdown of PHB in endothelial cells

Correspondence to: Professor Giuseppe Damante, Dipartimento di Scienze e Tecnologie Biomediche, Università di Udine, Piazzale Kolbe 1, 33100 Udine, Italy

E-mail: giuseppe.damante@uniud.it

Key words: thyroid tumors, prohibitin, transcription, alternative splicing increases the mitochondrial production of reactive oxygen species, resulting in cellular senescence (9). Accordingly, the modification of the mitochondrial PHB protein levels has been demonstrated during cellular senescence in cultured human fibroblasts (10). In the nucleus, PHB plays a role in controling gene transcription $(11,12)$. Structural/functional interactions with a number of transcription factors including p53, RB, E2F and the estrogen receptor, have been described $(3,13,14)$. In addition, it has been demonstrated that PHB interacts with chromatin-remodelling proteins (15).

There are conflicting data regarding the involvement of PHB in tumorigenesis. PHB has been shown to have either a permissive action on tumor growth or, alternatively, an oncosuppressive role, depending on the cell context (16). The micro-injection of PHB mRNA into mouse embryonic fibroblasts has been shown to block cell cycle progression (17). Moreover, PHB overexpression inhibits the androgendependent growth of prostate cells (18). However, it has been shown that PHB is required for the control of the RAS-induced RAF-MEK/-ERK activation (19). Moreover, the abrogation of PHB reduces proliferation and induces apoptosis in human hepatoma cells (20). In agreement with these latter observations, PHB has often been found to be overexpressed in many different human tumors (21).

Histone acetylation plays a major role in the control of gene transcription. Steady-state levels of histone acetylation are due to two classes of enzymes with opposing activity: Histone acetyltransferases and histone deacetylases (HDACs). HDAC action is inhibited by a number of different compounds that are collectively known as HDAC inhibitors (HDACis). HDACis have also been successful as anti-cancer drugs. These compounds have been shown to inhibit the proliferation of tumour cell lines in vitro and induce apoptosis and differentiation (22). Moreover, HDACis have been shown to suppress the growth of tumors in animal models (23). Thus, a number of HDACis are now being included in clinical trials for cancer treatment (24). HDACis induce histone hyperacetylation, and therefore they increase gene transcription. However, experimental data have indicated that HDACi effects are very heterogeneous, and, depending on the gene, either an increase or decrease in expression has been observed (25). The relevance of HDACis as anti-cancer drugs and the complexity of their effects call for detailed investigation on 
Table I. Oligonucleotide primers used in quantitative PCR reactions.

\begin{tabular}{llll}
\hline & \multicolumn{1}{c}{ Forward } & \multicolumn{1}{c}{ Reverse } & \multicolumn{1}{c}{ Probe } \\
\hline PHB & TCACACTGCGCATCCTCTTC & CAAAGCGAGCCACCACTGA & TCGCCAGCCAGCTTCCTCGC \\
PHB & TCCTCCCTTCTGCTTTGCTAGA & CTGCCTCACCTCAGCATGTT & TGAGACTTGAAAACACG \\
SHORT & & & \\
PHB & ATGTGCGGCTGAACTGAGAA & TCCCCGGCACCTCTCTTC & CCTCCGTCTTCCCAGCGGTTCC \\
3'UTR & & & \\
\hline
\end{tabular}

the molecular events induced by these compounds. In this study, we delineate the HDACi effects on $P H B$ gene transcription and PHB mRNA alternative splicing in thyroid tumor cells.

\section{Materials and methods}

Cell culture and transfection. TPC-1 and FRO cells were cultured in DMEM medium with $10 \%$ fetal bovin serum (Gibco, Milan, Italy). Transfections were performed using Lipofectamine reagent (Invitrogen) according to the manufacturer's instructions. Plasmids were used in the following amounts: $1 \mu \mathrm{g}$ PHB promoter-LUC, $1 \mu \mathrm{g}$ periostin promoterLUC, $0.33 \mu \mathrm{g}$ pcDNA3-HDAC1, $0.33 \mu \mathrm{g}$ pcDNA3-HDAC2, $0.33 \mu \mathrm{g}$ pcDNA3-HDAC3 and $1 \mu \mathrm{g}$ RSV-chloramphenicolacetyltransferase (CAT). Cells were harvested $48 \mathrm{~h}$ after transfection, and cell extracts were prepared by a standard freeze and thaw procedure. The transfection efficiency was normalized among the replicates by co-transfecting the RSVCAT plasmid which contains the Rous sarcoma virus promoter, with the CAT gene. CAT activity was measured by the ELISA method (Amersham, Milan, Italy). LUC activity was measured by a chemiluminescence procedure.

Viability assay. Three hours before the end of treatment with trichostatin A (TSA) or sodium butyrate $(\mathrm{NaB})$, a solution containing $4 \mathrm{mg} / \mathrm{ml}$ MTT in PBS was added to $10 \%$ of the culture medium. After $3 \mathrm{~h}$, the medium was removed and the cells were lysed with DMSO. The absorbances of the samples were analysed at a wavelength of $540 \mathrm{~nm}$ with background subtraction at $690 \mathrm{~nm}$. All experimental points were run in quadruplicate.

Quantitative RT-PCR. Total RNA from the cell lines was extracted using the RNeasy protect mini kit (Qiagen) according to the instructions of the manufacturer. Total RNA $(1 \mu \mathrm{g})$ was reverse transcribed to single-strand cDNA using random exaprimers and $200 \mathrm{U}$ MMLV reverse transcriptase (Invitrogen) in a final volume of $20 \mu \mathrm{l}$ at $42^{\circ} \mathrm{C}$ for $50 \mathrm{~min}$ followed by heating at $70^{\circ} \mathrm{C}$ for $15 \mathrm{~min}$. Real-time PCRs were performed using the ABI Prism 7300 Sequence Detection System (Applied Biosystems, Foster City, CA, USA). The oligonucleotide primers and probes for PHB are listed in Table I and their position in the $P H B$ gene is shown in Fig. 1. Oligonucleotide primers and probes for ASF/SF2 were purchased from Applied Biosystems as Assays-on-Demand gene expression products. Oligonucleotide primers and probes for the endogenous control, $\beta$-glucuronidase, have been previously described by Beillard et al (26). A $25 \mu 1$ reaction mixture containing $5 \mu \mathrm{l}$ cDNA template, $12.5 \mu \mathrm{l}$ TaqMan Universal PCR Master Mix (Applied Biosystems), and 1.25 $\mu 1$ primer probe mixture was amplified using the following thermal cycler parameters: Incubation at $50^{\circ} \mathrm{C}$ for 2 min and denaturation at $95^{\circ} \mathrm{C}$ for $10 \mathrm{~min}$, then 40 cycles of the amplification step (denaturation at $95^{\circ} \mathrm{C}$ for $15 \mathrm{sec}$ and annealing/ extension at $60^{\circ} \mathrm{C}$ for $1 \mathrm{~min}$ ). The $\Delta \mathrm{CT}$ method, by means of the SDS software (Applied Biosystems), was used to calculate the mRNA levels.

\section{Results}

In order to investigate the HDACi effects on PHB expression in human thyroid tumor cells, the TPC- 1 and FRO cell lines were used. TPC-1 cells are derived from papillary thyroid carcinoma, while FRO cells from anaplastic thyroid carcinoma (27). Doses of $300 \mathrm{nM}$ TSA and $3 \mathrm{mM} \mathrm{NaB}$ for 24-h stimulation, were used. In this condition, the effects of both drugs on cell viability were negligible (Fig. 2A). PHB expression was increased in both the TPC- 1 and FRO cells. However, the extent of increase was higher in the TPC-1 (4-5-fold) than in the FRO (2-fold) cell line (Fig. 2B). Nevertheless, these results indicate that histone acetylation plays a role in the control of PHB gene expression. It can be predicted that the overexpression of HDACs should have an inhibitory effect on PHB expression. Such a hypothesis was corroborated by a cell transfection approach. TPC-1 cells were transfected with a construct containing the PHB promoter linked to a reporter gene (LUC) and with the expression vectors for three members of class I HDACs. As shown in Fig. 3, the overexpression of HDAC1 exerted a strong inhibitory effect on PHB promoter activity. HDAC2 also showed inhibitory action, albeit to a lesser extent. On the contrary, HDAC3 did not exert any effect (Fig. 3). The lack of effect of HDAC3 is specific. When the same experiment was performed on the periostin promoter (28), a significant inhibitory effect was detected (Fig. 3).

In addition to gene transcription, HDACis have been known to control mRNA splicing (29). The PHB primary transcript is spliced out into two major isoforms (Fig. 1), that we refer to here as PHB 3'UTR and PHB SHORT. The PHB 3'UTR encodes for a longer isoform containing an untranslated sequence that is per se able to induce the blocking of proliferation (30). The SHORT isoform stops at exon 5, which differs at its 3'-terminus from the 3'UTR isoform (Fig. 1). Thus, we tested whether HDACis are able to affect PHB alternative splicing resulting in the quantitative modifi- 


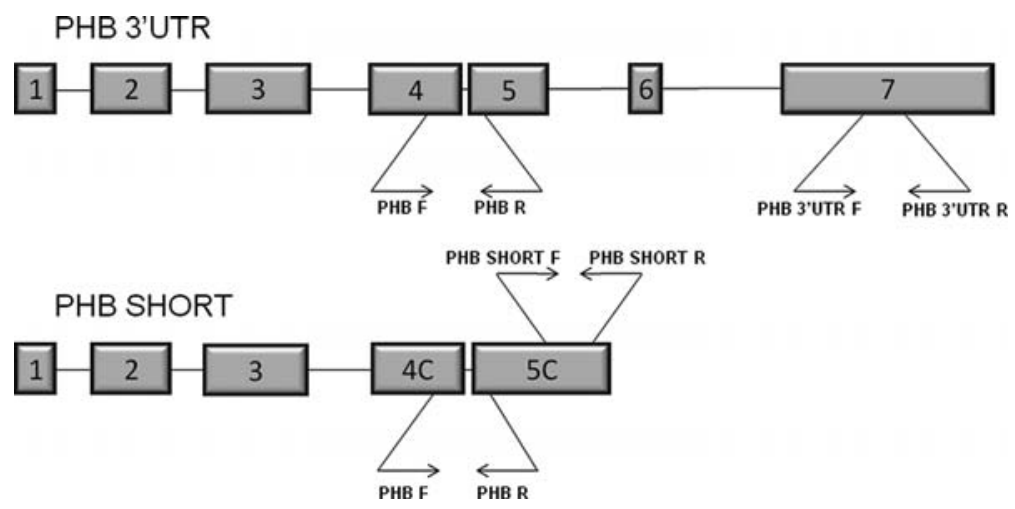

Figure 1. Schematic view of PHB mRNA isoforms. Exon-intron structures of PHB 3'UTR and PHB SHORT mRNA isoforms are shown. Exons are indicated by rectangles and introns by lines. Positions of forward (F) and reverse (R) primers for quantitative RT-PCR are indicated by arrows.

A
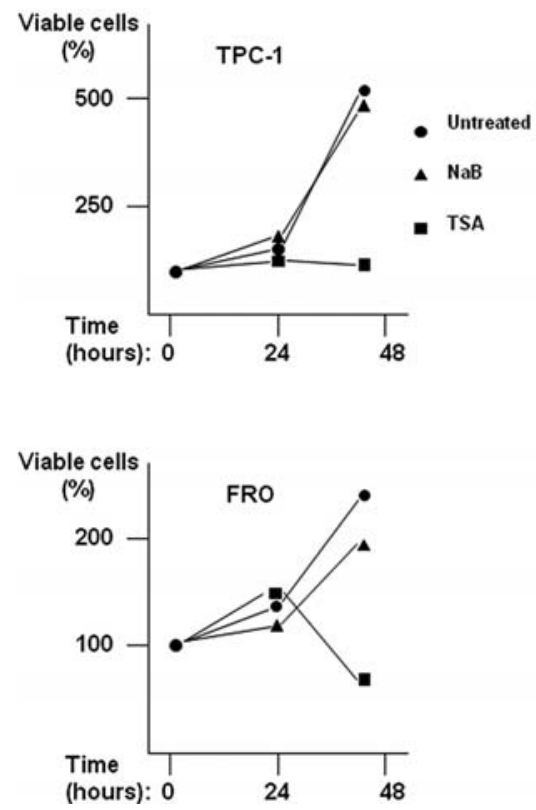

B

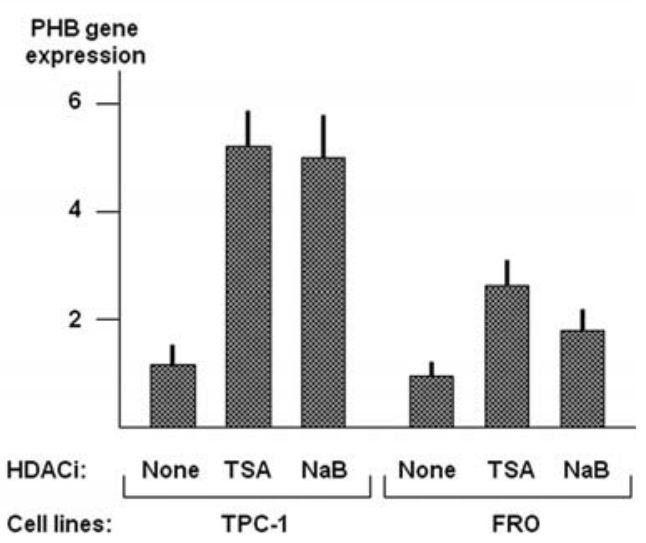

Figure 2. Effects of HDACi on cell viability and PHB mRNA levels of the TPC-1 and FRO cell lines. (A) Effects of TSA and NaB on cell viability. Black circles indicate untreated cells, triangles indicate NaB-treated cells and squares indicate TSA-treated cells. Each dot indicates the mean value of four independent determinations. (B) Effects of TSA and $\mathrm{NaB}$ on PHB mRNA levels. Each bar indicates the mean value \pm SD of three independent measures.
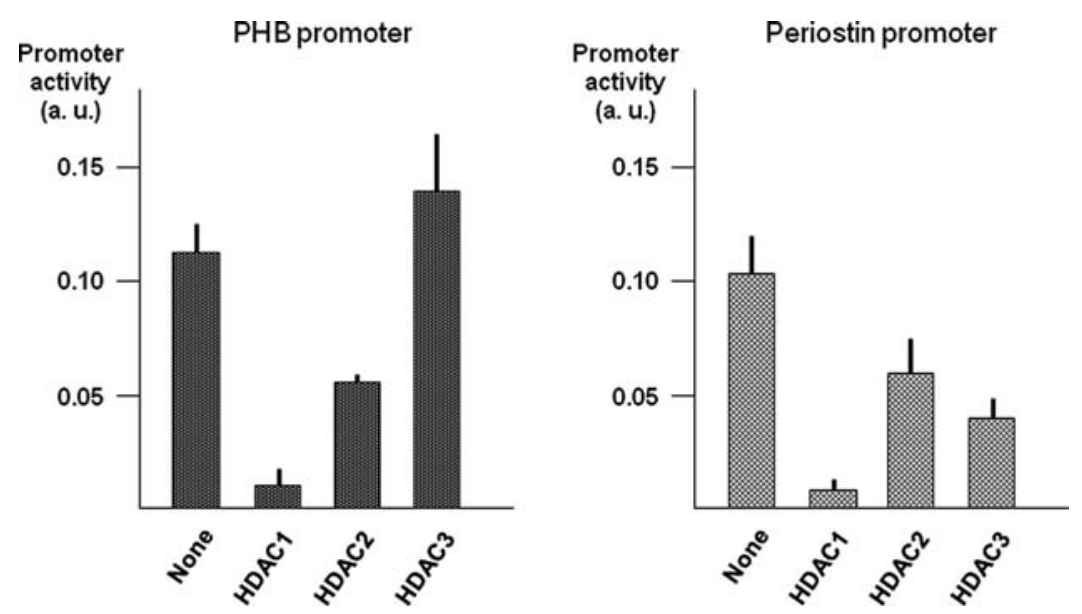

Figure 3. Effect of HDACs on PHB promoter activity. TPC-1 cells were co-transfected with plasmids containing either the PHB or the periostin promoter cloned in position 5' to the LUC gene and expression vectors for HDAC1,2 and 3. Efficiency of transfection among the replicates were normalized by using the RSV-CAT plasmid. Each bar indicates the mean value \pm SD of three independent transfections. a.u., arbitrary units. 

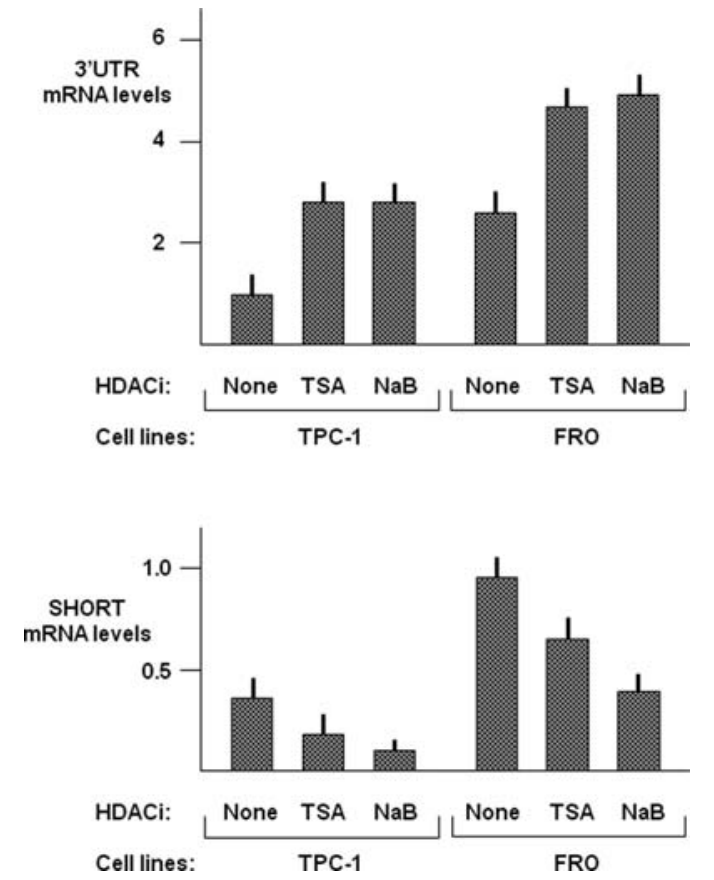

Figure 4. Effects of HDACi on 3'UTR and SHORT PHB mRNA isoforms. mRNA levels of 3'UTR and SHORT PHB isoforms were evaluated by quantitative RT-PCR as described in Materials and methods. Each bar indicates the mean value $\pm \mathrm{SD}$ of three independent measures.

cation of the two major isoforms. Specific assays were used to measure the two isoforms by quantitative RT-PCR (Fig. 1). Experimental results are shown in Fig. 4. In both cell lines the HDACi treatment induced the increase of the 3'UTR isoform. The increment was higher in the TPC- 1 than in the FRO cells. In contrast, the mRNA levels of the SHORT isoform were decreased by the HDACi treatment in both cell lines. Thus, the HDACi treatment affects PHB alternative splicing in thyroid tumour cell lines leading to the relative overexpression of the PHB 3'UTR isoform.

It has been shown that HDACi treatment can increase the levels of the ASF/SF2 splicing factor (31). Thus, the levels of ASF/SF2 mRNA were evaluated in TPC-1 and FRO cells treated or not with TSA or NaB. Neither compound had a significant effect on ASF/SF2 mRNA levels (data not shown), suggesting that the overexpression of the PHB 3'UTR isoform after HDACi treatment is not due to the modification of the ASF/SF2 expression.

\section{Discussion}

Distinct HDACis act by different mechanisms and, in addition to histone acetylation, they can induce other effects (32). For these reasons, to define that HDACi effects are bona fide due to histone acetylation, the same modification must be induced by at least two of these compounds. Thus, since both TSA and $\mathrm{NaB}$ were able to stimulate PHB expression, it can be ascertained that histone acetylation controls PHB gene expression. This statement is re-inforced by data indicating that the overexpression of HDAC1 and, to a lesser extent, that of HDAC2, have an inhibitory effect on PHB promoter activity. In contrast to HDAC1 and 2, HADC3 had no effect on the PHB promoter. This is consistent with the notion that distinct HDACs control gene expression in different ways and that HDAC3 has effects on gene expression quite different from those elicited by HDAC1 and 2. By using siRNA knockdown, it has been shown that HDAC1 and 3 act on different sets of genes with an overlap of only $\sim 30 \%$ (33). Moreover, the knockdown of HDAC3, but not that of HDAC1 or 2, increased cells in the $\mathrm{G} 2 / \mathrm{M}$ phase in human colon cancer cells (34). Gregoire et al have shown that HDAC3, but not HDAC1 and 2, efficiently deacetylated MEF2D in vitro and in vivo (35). In a recent study, it was shown that the silencing of HDAC3, but not that of HDAC1 and 2, reduced the migration and induced the expression of E-cadherin in ovarian cancer cells (36).

Many studies have indicated that treatment with HDACi affects mRNA splicing, resulting in the quantitative modification of mature mRNA species transcribed by a single gene. Such an effect has been reported for different genes including those encoding for the glucocorticoid receptor, the cystic fibrosis transmembrane conductance regulator, the X-linked inhibitor of apoptosis protein-associated factor 1 and the survival motor neuron 2 (37-39). Effects on this latter gene could have a relevance to the therapy of spinal muscular atrophy (40). Some of these effects are explained by the modification of the expression of splicing factors. Indeed, it has been shown that HDACi treatment modifies the expression of the ASF/SF2 splicing factor (31). Our data indicate, however, that in thyroid cancer cells the HDACi treatment does not modify ASF/SF2 expression. An alternative hypothesis is that histone modification could directly control alternative splicing. However, as recently shown, histone methylation, but not acetylation, plays a role in the direct control of alternative splicing (41). Our data indicate that in thyroid tumor cell lines HDACi treatment modifies the quantitative ratio between the two major mRNA species of the $P H B$ gene. Both TSA and NaB induced the increase of the PHB 3'UTR and the decrease of the PHB SHORT isoform. It has been previously shown that PHB 3'UTR has anti-proliferative activity (30), and that it inhibits colony formation in soft agar assays, and suppresses xenograft tumor growth when implanted on nude mice (42). Thus, PHB 3'UTR can be considered to be an oncosuppressor. Thus, the increase of PHB 3'UTR which was observed upon HDACi treatment could contribute to the reduction in cell viability induced by these compounds.

\section{Acknowledgements}

This study was funded by grants from MIUR to G.D. (PRIN no. 2007N8P32H_002). C.P. was supported by a grant from FIRC (Federazione Italiana Ricerca Cancro).

\section{References}

1. Mishra S, Murphy LC, Nyomba BL and Murphy LJ: Prohibitin: a potential target for new therapeutics. Trends Mol Med 11: 192-197, 2005.

2. Ikonen E, Fiedler K, Parton RG and Simons K: Prohibitin, an antiproliferative protein, is localized to mitochondria. FEBS Lett 358: 273-277, 1995.

3. Wang S, Fusaro G, Padmanabhan J and Chellappan SP: Prohibitin co-localizes with $\mathrm{Rb}$ in the nucleus and recruits $\mathrm{N}$ CoR and HDAC1 for transcriptional repression. Oncogene 21: 8388-8396, 2002. 
4. Morrow IC and Parton RG: Flotillins and the PHB domain protein family: rafts, worms and anaesthetics. Traffic 6: 725-740, 2005.

5. Rastogi S, Joshi B, Fusaro G and Chellappan S: Camptothecin induces nuclear export of prohibitin preferentially in transformed cells through a CRM-1-dependent mechanism. J Biol Chem 281: 2951-2959, 2006.

6. Vessal M, Mishra S, Moulik S and Murphy LJ: Prohibitin attenuates insulin-stimulated glucose and fatty acid oxidation in adipose tissue by inhibition of pyruvate carboxylase. FEBS J 273: 568-576, 2006

7. Jitrapakdee S and Wallace JC: Structure, function and regulation of pyruvate carboxylase. Biochem J 340: 1-16, 1999.

8. Nijtmans LG, de Jong L, Artal Sanz M, Coates PJ, Berden JA, Back JW, Muijsers AO, van der Spek H and Grivell LA: Prohibitins act as a membrane-bound chaperone for the stabilization of mitochondrial proteins. EMBO J 19: 2444-2451, 2000

9. Schleicher M, Shepherd BR, Suarez Y, Fernandez-Hernando C, Yu J, Pan Y, Acevedo LM, Shadel GS and Sessa WC. Prohibitin-1 maintains the angiogenic capacity of endothelial cells by regulating mitochondrial function and senescence. J Cell Biol 180: 101-112, 2008

10. Liu XT, Stewart CA, King RL, Danner DA, Dell'Orco RT and McClung JK: Prohibitin expression during cellular senescence of human diploid fibroblasts. Biochem Biophys Res Commun 201: 409-414, 1994

11. Gamble SC, Odontiadis M, Waxman J, Westbrook JA, Dunn MJ, Wait R, Lam EW and Bevan CL: Androgens target prohibitin to regulate proliferation of prostate cancer cells. Oncogene 23 : 2996-3004, 2004.

12. Kurtev V, Margueron R, Kroboth K, Ogris E, Cavailles V and Seiser C: Transcriptional regulation by the repressor of estrogen receptor activity via recruitment of histone deacetylases. J Biol Chem 279: 24834-24843, 2004

13. Fusaro G, Dasgupta P, Rastogi S, Joshi B and Chellappan S: Prohibitin induces the transcriptional activity of p53 and is exported from the nucleus upon apoptotic signaling. J Biol Chem 278: 47853-47861, 2003.

14. Wang S, Zhang B and Faller DV: Rb and prohibitin target distinct regions of $\mathrm{E} 2 \mathrm{~F} 1$ for repression and respond to different upstream signals. Mol Cell Biol 19: 7447-7460, 1999

15. Wang S, Zhang B and Faller DV: BRG1/BRM and prohibitin are required for growth suppression by estrogen antagonists. EMBO J 23: 2293-2303, 2004

16. Mishra S, Murphy LC and Murphy LJ: The Prohibitins: emerging roles in diverse functions. J Cell Mol Med 10: 353-363, 2006

17. McClung JK, Danner DB, Stewart DA, Smith JR, Schneider EL Lumpkin CK, Dell'Orco RT and Nuell MJ: Isolation of a cDNA that hybrid selects antiproliferative mRNA from rat liver. Biochem Biophys Res Commun 164: 1316-1322, 1989

18. Dart DA, Spencer-Dene B, Gamble SC, Waxman J and Bevan CL: Manipulating prohibitin levels provides evidence for an in vivo role in androgen regulation of prostate tumours. Endocr Relat Cancer 16: 1157-1169, 2009

19. Rastogi S, Joshi B, Dasgupta P, Morris M, Wright K and Chellappan S: Prohibitin facilitates cellular senescence by recruiting specific corepressors to inhibit E2F target genes. Mol Cell Biol 26: 4161-4171, 2006.

20. Sánchez-Quiles V, Santamaría E, Segura V, Sesma L, Prieto J and Corrales FJ: Prohibitin deficiency blocks proliferation and induces apoptosis in human hepatoma cells: molecular mechanisms and functional implications. Proteomics 10: 1609-1620, 2010 .

21. Czarnecka AM, Campanella C, Zummo G and Cappello F: Mitochondrial chaperones in cancer: from molecular biology to clinical diagnostics. Cancer Biol Ther 5: 714-720, 2006.

22. Martínez-Iglesias O, Ruiz-Llorente L, Sánchez-Martínez R, García L, Zambrano A and Aranda A: Histone deacetylase inhibitors: mechanism of action and therapeutic use in cancer. Clin Transl Oncol 10: 395-398, 2008.

23. Marks PA, Richon VM, Breslow R and Rifkind RA: Histone deacetylase inhibitors as new anticancer drugs. Curr Opin Oncol 13: 477-483, 2001

24. Marks PA and $\mathrm{Xu}$ WSJ: Histone deacetylase inhibitors Potential in cancer therapy. Cell Biochem 107: 600-608, 2009.
25. Buchwald M, Krämer $\mathrm{OH}$ and Heinzel T: HDACi-targets beyond chromatin. Cancer Lett 280: 160-167, 2009.

26. Beillard E, Pallisgaard N, van der Velden VH, Bi W, Dee R, van der Schoot E, Delabesse E, Macintyre E, Gottardi E, Saglio G, Watzinger F, Lion T, van Dongen JJ, Hokland P and Gabert J: Evaluation of candidate control genes for diagnosis and residual disease detection in leukemic patients using 'realtime' quantitative reverse-transcriptase polymerase chain reaction (RQ-PCR) - a Europe against cancer program. Leukemia 17: 2474-2486, 2003

27. Schweppe RE, Klopper JP, Korch C, Pugazhenthi U, Benezra M, Knauf JA, Fagin JA, Marlow LA, Copland JA, Smallridge RC and Haugen BR: Deoxyribonucleic acid profiling analysis of 40 human thyroid cancer cell lines reveals cross-contamination resulting in cell line redundancy and misidentification. J Clin Endocrinol Metab 93: 4331-4341, 2008.

28. Puppin C, Fabbro D, Dima M, Di Loreto C, Puxeddu E, Filetti S, Russo D and Damante G: High periostin expression correlates with aggressiveness in papillary thyroid carcinomas. J Endocrinol 197: 401-408, 2008.

29. Kuhn AN, van Santen MA, Schwienhorst A, Urlaub H and Lührmann R: Stalling of spliceosome assembly at distinct stages by small-molecule inhibitors of protein acetylation and deacetylation. RNA 15: 153-175, 2009

30. Jupe ER, Liu XT, Kiehlbauch JL, McClung JK and Dell'Orco RT: The 3' untranslated region of prohibitin and cellular immortalization. Exp Cell Res 224: 128-135, 1996.

31. Brichta L, Hofmann Y, Hahnen E, Siebzehnrubl FA, Raschke H, Blumcke I, Eyupoglu IY and Wirth B: Valproic acid increases the SMN2 protein level: a well-known drug as a potential therapy for spinal muscular atrophy. Hum Mol Genet 12: 2481-2489, 2003

32. Zhong $\mathrm{S}$, Goto $\mathrm{H}$, Inagaki $\mathrm{M}$ and Dong $\mathrm{Z}$ : Phosphorylation at serine 28 and acetylation at lysine 9 of histone $\mathrm{H} 3$ induced by trichostatin A. Oncogene 22: 5291-5297, 2003.

33. Senese S, Zaragoza K, Minardi S, Muradore I, Ronzoni S, Passafaro A, Bernard L, Draetta GF, Alcalay M, Seiser C and Chiocca S: Role for histone deacetylase 1 in human tumor cell proliferation. Mol Cell Biol 27: 4784-4795, 2007.

34. Wilson AJ, Byun DS, Popova N, Murray LB, L'Italien K, Sowa Y, Arango D, Velcich A, Augenlicht LH and Mariadason JM: Histone deacetylase 3 (HDAC3) and other class I HDACs regulate colon cell maturation and p21 expression and are deregulated in human colon cancer. J Biol Chem 281: 13548-13558, 2006.

35. Grégoire S, Xiao L, Nie J, Zhang X, Xu M, Li J, Wong J, Seto E and Yang XJ: Histone deacetylase 3 interacts with and deacetylates myocyte enhancer factor 2. Mol Cell Biol 27: 1280-1295, 2007

36. Hayashi A, Horiuchi A, Kikuchi N, Hayashi T, Fuseya C, Suzuki A, Konishi I and Shiozawa T: Type-specific roles of histone deacetylase (HDAC) overexpression in ovarian carcinoma: HDAC1 enhances cell proliferation and HDAC3 stimulates cell migration with downregulation of E-cadherin. Int J Cancer 127: 1332-1346, 2010

37. Piotrowska $\mathrm{H}$ and Jagodzinski PP: Trichostatin A, sodium butyrate, and 5-aza-20-deoxycytidine alter the expression of glucocorticoid receptor $\mathrm{a}$ and $\mathrm{b}$ isoforms in Hut-78 T- and Raji B-lymphoma cell lines. Biomed Pharmacother 61: 451-454, 2007.

38. Fang X, Liu Z, Fan Y, Zheng C, Nilson S, Egevad L, Ekman P and $\mathrm{Xu} \mathrm{D}$ : Switch to full-length of XAF1mRNA expression in prostate cancer cells by the DNA methylation inhibitor. Int J Cancer 118: 2485-2489, 2006

39. Nissim-Rafinia M, Aviram M, Randell SH, Shushi L, Ozeri E, Chiba-Falek O, Eidelman O, Pollard HB, Yankaskas JR and Kerem B: Restoration of the cystic fibrosis transmembrane conductance regulator function by splicing modulation. EMBO Rep 5: 1071-1077, 2004

40. Chang JG, Hsieh-Li HM, Jong YJ, Wang NM, Tsai CH and Li H: Treatment of spinal muscular atrophy by sodium butyrate. Proc Natl Acad Sci USA 98: 9808-9813, 2001

41. Luco RF, Pan Q, Tominaga K, Blencowe BJ, Pereira-Smith OM and Misteli T: Regulation of alternative splicing by histone modifications. Science 327: 996-1000, 2010.

42. Manjeshwar S, Branam DE, Lerner MR, Brackett DJ and Jupe ER: Tumor suppression by the prohibitin gene 3'untranslated region RNA in human breast cancer. Cancer Res 63: 5251-5256, 2003 